\title{
Correlações do índice de área do cladódio com características morfogênicas e produtivas da palma forrageira
}

\author{
Karina Mendes Pinheiro(1), Thieres George Freire da Silva(1), Herica Fernanda de Sousa Carvalho(1), \\ Jannaylton Everton Oliveira Santos ${ }^{(1)}$, José Edson Florentino de Morais ${ }^{(1)}$, \\ Sérgio Zolnier(2) e Djalma Cordeiro dos Santos ${ }^{(3)}$
}

\begin{abstract}
(1)Universidade Federal Rural do Pernambuco, Unidade Acadêmica de Serra Talhada, Caixa Postal 063, CEP 56900-000 Serra Talhada, PE, Brasil.E-mail: k.agro20@yahoo.com.br, thieres_freire@yahoo.com.br, hericadernanda_17@hotmail.com, jannaylton_t.a2007@hotmail.com, joseedson50@hotmail.com (2)Universidade Federal de Viçosa, Avenida P. H. Rolfs, s/noo, CEP 36570-900 Viçosa, MG, Brasil. E-mail: zolnier@ufv.br ${ }^{(3)}$ Instituto Agronômico de Pernambuco, BR 232, Km 253, CEP 56500-000 Arcoverde, PE, Brasil. E-mail: djalma.cordeiro@ipa.br
\end{abstract}

Resumo - O objetivo deste trabalho foi avaliar as correlações do índice de área do cladódio com características morfogênicas e produtivas da palma forrageira (Nopalea sp. e Opuntia sp.). Foram avaliados três clones de palma forrageira, em condições de sequeiro: IPA Sertânia, Miúda e Orelha de Elefante Mexicana. Dados morfológicos dos cladódios e da planta, índice de área do cladódio e biomassa acumulada foram obtidos na ocasião da colheita. A relação entre os dados coletados foi avaliada por meio da análise de trilha, após a aplicação da matriz de correlação de Pearson e do teste de multicolinearidade. Foram observadas maiores correlações das características morfogênicas com o rendimento da cultura do que com o índice de área do cladódio, com $\mathrm{R}^{2}$ entre 0,5930 e 0,9502 . As variáveis altura x largura e número total de cladódios foram as que melhor explicaram a variação do índice de área do cladódio. O número total de cladódios, o índice de área do cladódio e a morfologia dos cladódios de quarta ordem são as variáveis que melhor explicam a variabilidade do rendimento dos clones de palma forrageira avaliados em ambiente semiárido.

Termos para indexação: Nopalea, Opuntia, análise de trilha, biomassa, rendimento clonal, semiárido.

\section{Correlations of the cladode area index with morphogenetic and yield traits of cactus forage}

\begin{abstract}
The objective of this work was to evaluate the correlations of the cladode area index with morphogenetic and yield traits of the cactus forage (Nopalea sp. and Opuntia sp.). Three clones of cactus forage were evaluated in dry land conditions: IPA Sertânia, Miúda, and Orelha de Elefante Mexicana. Morphological data from cladode and plant, cladode area index, and accumulated dry biomass were obtained at harvest. The relationship between the collected data was analyzed by path analysis, after the application of Pearson's correlation matrix and the multicollinearity test. Higher correlations of morphogenetic traits were observed with crop yield than with the cladode area index, with $\mathrm{R}^{2}$ between 0.5930 and 0.9502 . The variables height $\mathrm{x}$ width and total number of cladodes were the ones that best explained the variation of the cladode area index. The total number of cladodes, the cladode area index, and the morphology of fourth-order cladodes are the variables that best explain the yield variability of the cactus forage clones evaluated in semiarid environment.
\end{abstract}

Index terms: Nopalea, Opuntia, path analysis, biomass, clonal yield, semiarid.

\section{Introdução}

A palma forrageira (Nopalea sp. e Opuntia sp.) tem sido bastante cultivada no semiárido brasileiro, para alimentação animal. A planta é tolerante a períodos de longas estiagens, apresenta metabolismo fisiológico diferenciado - conhecido como metabolismo ácido das Crassuláceas - e pode tolerar altas temperaturas e deficit hídrico, bem como acumular fitomassa (Lopes et al., 2007). Por sua capacidade de suportar essas condições, destaca-se como reserva forrageira que contribui para a sustentabilidade da pecuária, segmento que, na região, é atingido pela escassez de alimentos (Oliveira et al., 2010).

A interação entre plantas e ambiente condiciona a produção vegetal, que está diretamente relacionada ao aproveitamento da energia solar, transformada pelas folhas em energia química durante o processo fotossintético. Diversos fatores são importantes para a determinação da interceptação luminosa, como hábito 
de crescimento da planta, ângulo foliar e disposição das folhas no dossel (Fagundes et al., 2001), os quais definirão o rendimento da cultura (Maldaner et al., 2009).

Na palma forrageira, o uso da radiação é processado pelo cladódio, que promove a produção de carboidratos e de biomassa seca. A cultura apresenta baixo índice de área do cladódio, quando comparada a espécies leguminosas, o que resulta em uma menor taxa de acúmulo de biomassa (Oliveira et al., 2007). Essa característica, no entanto, também depende do clone, que apresenta diferentes morfologias de emissão, tamanho, formato e distribuição dos cladódios. Essa diferenciação pode influenciar a capacidade fotossintetizante e o rendimento da palma forrageira (Silva et al., 2010).

A relação entre as características morfológicas - como altura e largura da planta, índice de área do cladódio e comprimento do cladódio - e o rendimento da planta representa um dado de grande importância para a compreensão da resposta da palma forrageira às condições do ambiente de cultivo. Estudos mostram que essa informação permite o acompanhamento do acúmulo de forragem e uma estimativa de sua qualidade, os quais podem ser melhorados com a adequação de práticas de manejo ao longo do ciclo da cultura (Costa et al., 2012). Em áreas de cultivo submetidas a diferentes manejos, Dubeux Junior et al. (2006) observaram variação do rendimento do clone IPA 20 de palma forrageira, em razão do índice de área do cladódio. Silva et al. (2010) também constataram a influência de características morfológicas na produtividade de clones de palma forrageira. Já Neder et al. (2013) relataram que a produção de matéria verde, o número e a espessura dos cladódios podem ser utilizados na seleção de acessos da espécie Opuntia ficus-indica. Para outras culturas, a produtividade tem sido relacionada aos componentes de produção (Fırıncioğlu et al., 2010; Lu et al., 2011) e às variáveis meteorológicas (Rao et al., 1998).

A aplicação de correlações lineares, por meio da análise de trilha, é uma ferramenta que permite conhecer os efeitos direto e indireto, por exemplo, da influência das características dos cladódios sobre o índice de área do cladódio da planta e desses efeitos sobre a produtividade da palma forrageira (Silva et al., 2010; Neder et al., 2013). As correlações lineares possibilitam avaliar o quanto da alteração de um caráter pode ser afetada pelos demais (Cruz et al., 2004). A maioria das correlações é explicada pelos efeitos aditivos dos genes, o que afeta simultaneamente dois caracteres (Vencovsky \& Barriga, 1992). Contudo, a decomposição da correlação depende do conjunto de caracteres estudados, que pode assumir valor positivo, negativo ou igual a zero (Kurek et al., 2001). Nesse tipo de análise, o grau de multicolinearidade entre as variáveis explicativas ou respostas deve ser analisado, uma vez que pode super ou subestimar os efeitos diretos ou indiretos (Toebe \& Cargnelutti Filho, 2013).

Apesar dos avanços científicos na relação entre as características morfogênicas e produtivas da palma forrageira, há uma lacuna na literatura quanto a pesquisas referentes aos clones IPA Sertânia [Nopalea cochenillifera (L.) Salm-Dyck], Miúda ( $N$. cochenillifera) e Orelha de Elefante Mexicana [Opuntia stricta (Haw.) Haw.]. Esses clones são resistentes à praga cochonilha-do-carmim (Dactylopius sp.), e suas áreas de cultivo estão em expansão no Nordeste brasileiro (Vasconcelos et al., 2009).

O objetivo deste trabalho foi avaliar as correlações do índice de área do cladódio com características morfogênicas e produtivas da palma forrageira.

\section{Material e Métodos}

Os dados foram coletados simultaneamente em três áreas de cultivo $\left(7^{\circ} 55^{\prime} \mathrm{S}, 38^{\circ} 17^{\prime} \mathrm{W}\right.$, a $497 \mathrm{~m}$ de altitude), entre setembro e novembro de 2013, cada uma com um clone de palma forrageira, pertencente ao Banco Ativo de Germoplasma do Instituto Agronômico de Pernambuco (IPA), em Serra Talhada, na região semiárida da microrregião do Vale do Pajeú. O clima do local é do tipo BSh, de acordo com a classificação de Köppen.

Foram avaliados três clones de palma forrageira: IPA Sertânia, do gênero Nopalea, com cinco anos e um mês de idade, em espaçamento 1,5x0,3 m; Miúda, do gênero Nopalea, com quatro anos e oito meses de idade, em espaçamento 1,5x0,5 m; e Orelha de Elefante Mexicana, do gênero Opuntia, com quatro anos de idade, em espaçamento $1,5 \times 0,5 \mathrm{~m}$. O plantio das três áreas, com dimensões de 50x30 m, foi realizado em setembro de 2008, para IPA Sertânia; em fevereiro de 2009, para Miúda; e em outubro de 2009, para Orelha de Elefante Mexicana. Nessa ocasião, os cladódios foram colocados em sulcos e enterrados até $50 \%$ de seu 
comprimento. Ao longo do ciclo, a adubação e os tratos culturais foram realizados conforme recomendação do IPA. As áreas foram mantidas em condições de sequeiro durante todo o ciclo da cultura.

Em cada uma das três áreas de cultivo, foram escolhidas cinco subáreas de 12 plantas, com três fileiras de quatro plantas cada uma, ou seja, 60 plantas por clone, o que totalizou 180 plantas e 15 parcelas. Procedimento semelhante foi adotado para acessos de palma forrageira, por Silva et al. (2010).

As características morfogênicas foram medidas na ocasião da colheita, entre setembro e novembro de 2013, tendo-se registrado os valores biométricos da planta e dos cladódios. Nas plantas, analisou-se a altura, a largura e o número de cladódios por ordem. A altura foi medida desde a superfície do solo até o cladódio mais alto, enquanto a largura foi obtida ao se utilizar as suas duas maiores dimensões como referência; ambas as variáveis foram medidas com auxílio de fita métrica. Em seguida, as plantas foram cortadas, tendose deixado apenas o cladódio basal; identificadas de acordo com a numeração da planta, a quantidade e a ordem de surgimento dos cladódios; e pesadas individualmente em campo, para evitar perda de água, para determinação da massa da planta em base fresca. Todos os cladódios foram colocados em sacos de ráfia e levados para o laboratório, para pesagem e biometria individual. Nessa etapa, foram medidos o comprimento, a largura, o perímetro e a espessura dos cladódios, por meio de fita métrica, tendo-se considerado as partes de maior comprimento e largura, e o contorno, para se obter o perímetro. A espessura foi medida com auxílio de paquímetro, na região mediana do cladódio.

Após as medidas biométricas, todos os cladódios das 180 plantas foram escaneados em escâner comercial, para gerar imagens "tagged image file format" (TIFF), com resolução de 200 dpi, para obtenção da área individual dos cladódios. Essas imagens foram processadas no programa computacional Lafore (Veiko Lehsten, Landscape Ecology Group, University of Oldenburg, Oldenburg, Alemanha), que classifica a área com base na tonalidade esverdeada da imagem. Os valores gerados foram usados no cálculo do índice de área do cladódio de cada planta:

$$
\mathrm{IACr}=\left(\sum_{\mathrm{n}}^{\mathrm{i}=1} \mathrm{AC}\right) / 10000 /(\mathrm{E} 1 \times \mathrm{E} 2),
$$

em que: IAC é o índice de área do cladódio observado, em $\mathrm{m}^{2} \mathrm{~m}^{-2} ; 10.000$ é o fator de conversão de $\mathrm{cm}^{2}$ para $\mathrm{m}^{2}$; e E1 $\times \mathrm{E} 2$ é o espaçamento entre fileiras e plantas de cada clone.

Ao final das medições, com os valores biométricos foram obtidas as seguintes características morfológicas dos três clones: altura e largura da planta; número total de cladódios; índice de área do cladódio; comprimento de cladódios de primeira a quinta ordem; largura dos cladódios de primeira a quinta ordem; espessura média dos cladódios de primeira a quinta ordem; e perímetro dos cladódios de primeira a quinta ordem.

Cinco plantas de tamanho mediano foram selecionadas por clone para obtenção da matéria seca. Todos os cladódios foram fragmentados $\mathrm{e}$ acondicionados em sacos de papel, identificados e levados para estufa de ventilação forçada a $65^{\circ} \mathrm{C}$, até atingir peso constante. As massas fresca e seca das cinco plantas foram usadas para determinar o conteúdo médio de matéria seca, para o cálculo do rendimento em base seca das demais plantas. Os dados foram extrapolados para $\mathrm{Mg} \mathrm{ha}^{-1}$, por meio da multiplicação do valor da massa seca de cada planta pela densidade de plantio inicial de cada clone, calculada conforme os valores de seus respectivos espaçamentos, anteriormente citados.

Foram avaliadas as relações das características morfológicas dos cladódios e da planta com o índice de área do cladódio, além dos efeitos dessas no rendimento. Para tanto, realizou-se, primeiramente, a correlação de Pearson entre as variáveis morfológicas explicativas e as variáveis respostas:

$$
r_{(X Y)}=\frac{\operatorname{Cov}(X, Y)}{\sqrt{\mathrm{V}(\mathrm{X}) \cdot \mathrm{V}(\mathrm{Y})}}=\frac{\sigma(\mathrm{X}, \mathrm{Y})}{\sigma(\mathrm{X}) \cdot \sigma(\mathrm{Y})},
$$

em que $r_{(X Y)}$ é o coeficiente de correlação de Pearson; $\sigma(\mathrm{X}, \mathrm{Y})$ é a covariância entre as características morfológicas $\mathrm{X}$ e as variáveis respostas $\mathrm{Y}$ (índice de área do cladódio ou rendimento); $\sigma(\mathrm{X})$ é o desvio-padrão das variáveis morfológicas; e $\sigma(\mathrm{Y})$ é o desvio-padrão da variável resposta.

A significância dos valores de $r_{(X Y)}$ foi avaliada, tendo-se assumido normalidade bivariada (Ho: $p=0$, em que a correlação é estatisticamente igual a zero), a 1 e $5 \%$ de probabilidade pelo teste $t$ de Student:

$$
\mathrm{tc}=\mathrm{r}_{(\mathrm{XY})} \sqrt{\mathrm{n}-2} / \sqrt{1-\mathrm{r}_{(\mathrm{XY})}^{2}},
$$

em que: tc é o valor de $\mathrm{t}$ de Student calculado e n é o número de dados usados, dependente do clone; tc não 
é rejeitado se $\mid$ tc $\mid<\mathrm{t}(\alpha / 2-2)$, para grau de liberdade de 59.

As variáveis explicativas que apresentaram efeito significativo do coeficiente de correlação de Pearson foram submetidas ao teste de multicolinearidade, para evitar problemas de intensificação dos efeitos das variáveis explicativas. Esse diagnóstico foi estabelecido ao se considerar, como referência, o número de condição $(\mathrm{NC})$ - razão entre o maior e o menor autovalor da matriz - inferior a 100 , ou seja, que a multicolinearidade é fraca. Nos casos em que houve multicolinearidade de moderada a forte $(100<\mathrm{NC}<1.000)$ ou severa $(\mathrm{NC} \geq 1.000)$, de acordo com Toebe \& Cargnelutti Filho (2013), adotou-se o procedimento de descarte de variáveis que contribuíram para o aparecimento da multicolinearidade e realizouse a análise de trilha em crista, em que se atribui uma constante à diagonal da matriz de correlação.

No estudo dos efeitos diretos e indiretos das variáveis explicativas sobre as respostas, inicialmente foi considerada como variável resposta o índice de área do cladódio. Em seguida, o índice de área do cladódio foi incluso como variável explicativa, juntamente com as demais características morfológicas, para analisar a variável resposta rendimento. Assim, aplicouse a análise de trilha, que assume o coeficiente de correlação parcial para a avaliação da relação entre duas variáveis (uma explicativa e outra resposta), tendo-se desconsiderado o efeito das demais:

$$
r_{(X i Y, Z)}=r_{X i}-r_{X i Z} \cdot r_{Y Z} / \sqrt{\left(1-r_{X i Z}^{2}\right) \cdot\left(1-r^{2}{ }_{Y Z}\right)},
$$

em que i refere-se a uma variável morfológica; $r_{\mathrm{XiZ}}$ é o coeficiente de correlação entre uma variável morfológica e enésimas variáveis explicativas; e $\mathrm{r}_{\mathrm{YZ}}$ é o coeficiente de correlação entre o rendimento e enésimas variáveis explicativas. A significância da correlação parcial foi igual à usada na correlação de Pearson (Cruz et al., 2004). Todas as análises foram feitas no programa computacional Genes (Cruz, 2013).

\section{Resultados e Discussão}

Para o clone IPA Sertânia, apenas altura x largura $(\mathrm{r}=0,5971)$ e número total de cladódios apresentaram efeito significativo sobre o índice de área do cladódio (Tabela 1). Essas variáveis explicativas apresentaram correlação positiva, mas de magnitude mediana, conforme classificação de Martins \& Domingues
(2011). Ao se analisar as correlações das características morfológicas, inclusive do índice de área do cladódio, com o rendimento, constatou-se que essas foram positivas e medianas, com destaque para o número total de cladódios, com maior magnitude da correlação. Observou-se que a magnitude do índice de área do cladódio de clones de palma forrageira se associa ao número de cladódios presentes na planta e ao hábito de crescimento da cultura (Dubeux Junior et al., 2006; Oliveira Junior et al., 2009).

Com a aplicação do teste de multicolinearidade nas características significativas $(\mathrm{p}<0,01$ ou $\mathrm{p}<0,05)$, a maior parte das variáveis não foi usada na análise de trilha, para desdobramento das correlações fenotípicas em efeito direto e indireto. Para IPA Sertânia, verificouse que as variáveis analisadas tiveram efeito de 49,51\% sobre a variação do índice de área do cladódio. Embora a correlação tenha sido positiva, a magnitude foi baixa para o efeito direto de altura $\mathrm{x}$ largura, enquanto $\mathrm{o}$

Tabela 1. Desdobramento das correlações fenotípicas do índice de área do cladódio e do rendimento do clone IPA Sertânia de palma forrageira (Nopalea cochenillifera), com cinco anos e um mês de idade, em condições de sequeiro, no semiárido brasileiro.

\begin{tabular}{|c|c|c|}
\hline Efeito & Variável explicativa & $\mathrm{r}$ \\
\hline & Índice de área do cladódio & \\
\hline Direto & Altura x largura & 0,2340 \\
\hline Indireto & Número total de cladódios & 0,3631 \\
\hline Total & & $0,5971^{*}$ \\
\hline Direto & Número total de cladódios & 0,5200 \\
\hline Indireto & Altura x largura & 0,1634 \\
\hline Total & & $0,6834^{*}$ \\
\hline$\overline{\mathrm{R}^{2}}$ & & 0,4951 \\
\hline \multirow[t]{2}{*}{ Variável residual } & & 0,7106 \\
\hline & Rendimento & \\
\hline Direto & Índice de área do cladódio & 0,1113 \\
\hline Indireto & Altura $x$ largura & 0,0993 \\
\hline Indireto & Número total de cladódios & 0,3837 \\
\hline Total & & $0,5942 *$ \\
\hline Direto & Altura x largura & 0,1663 \\
\hline Indireto & Índice de área do cladódio & 0,0664 \\
\hline Indireto & Número total de cladódios & 0,3920 \\
\hline Total & & $0,6247 *$ \\
\hline Direto & Número total de cladódios & 0,5614 \\
\hline Indireto & Índice de área do cladódio & 0,0760 \\
\hline Indireto & Altura x largura & 0,1161 \\
\hline Total & & $0,7535^{*}$ \\
\hline$\overline{\mathrm{R}^{2}}$ & & 0,5930 \\
\hline Variável residual & & 0,6379 \\
\hline
\end{tabular}

*Significativo pelo teste $\mathrm{t}$, a $5 \%$ de probabilidade. $\mathrm{R}^{2}$, coeficiente de determinação. 
número total de cladódios, mesmo de magnitude baixa, apresentou maior influência, em razão dos efeitos diretos e indiretos. Quanto ao rendimento, a correlação apresentou-se positiva e mediana, com $59,30 \%$ de sua variação explicada, sobretudo, pelas variáveis índice de área do cladódio, altura x largura e número total de cladódios; esta última se destacou pela maior contribuição direta e indireta. O clone IPA Sertânia não apresenta grande número de cladódios; no entanto, o seu hábito de crescimento semiaberto permite que as plantas tenham maior aproveitamento fotossintético, além de evitar o auto sombreamento, o que induz ao maior crescimento dos cladódios (Leite, 2009). A influência direta do número total de cladódios se reflete na maior magnitude do índice de área do cladódio; essa medida é útil para se estimar a capacidade fotossintética da palma, que pode ser usada na mensuração do crescimento vegetativo e permite refletir os efeitos do manejo sobre o desenvolvimento da cultura (Oliveira Junior et al., 2009).

Dubeux Junior et al. (2006), ao avaliarem a resposta do clone IPA 20 de palma forrageira, em quatro locais do semiárido do Estado de Pernambuco, relataram que o número de cladódios foi superior na menor densidade de plantas, em virtude da maior superfície de solo explorado. Esse hábito de crescimento foliar influencia a absorção de luz no dossel e, consequentemente, a fotossíntese da planta (Deckmyn et al., 2000). Como reflexo do número total de cladódios, pôde-se constatar que IPA Sertânia apresentou correlação moderada, com efeito direto sobre o rendimento. Dessa forma, é possível perceber que a menor quantidade de emissão de cladódios pelo clone pode ser compensada pelo seu tamanho.

Para o clone Miúda, as variáveis morfológicas altura x largura; número total de cladódios; largura média dos cladódios de primeira e segunda ordem; comprimento médio dos cladódios de segunda, terceira e quarta ordem; espessura média dos cladódios de segunda e terceira ordem; e perímetro médio dos cladódios de segunda, terceira e quarta ordem apresentaram correlação significativa $(\mathrm{p}<0,05)$ e positiva com o índice de área do cladódio (Tabela 2). Entretanto, a correlação foi classificada como de magnitude baixa. O desdobramento das variáveis biométricas do clone Miúda revelou que as características morfogênicas apresentaram contribuição em apenas $29,21 \%$ da variação do índice de área do cladódio. A maioria das características apresentou magnitude baixa, com exceção do comprimento dos cladódios de quarta ordem, para o qual a correlação foi positiva e moderada, e do perímetro dos cladódios de quarta ordem, que apresentou correlação negativa e moderada.

Tabela 2. Desdobramento das correlações fenotípicas do índice de área do cladódio do clone Miúda de palma forrageira (Nopalea cochenillifera), com quatro anos e oito meses de idade, em condições de sequeiro, no semiárido brasileiro.

\begin{tabular}{|c|c|c|c|}
\hline Efeito & Variável explicativa & $\mathrm{r}$ parcial & $\mathrm{r}$ total \\
\hline Direto & Altura x largura & 0,2307 & \\
\hline Indireto & CM dos cladódios de $4^{\mathrm{a}}$ ordem & 0,4440 & $0,4870^{*}$ \\
\hline Indireto & Total das demais variáveis & $-0,1878$ & \\
\hline Direto & Número total de cladódios & 0,1744 & \\
\hline Indireto & CM dos cladódios de $4^{\text {a }}$ ordem & 0,3493 & $0,4718 *$ \\
\hline Indireto & Total das demais variáveis & $-0,0520$ & \\
\hline Direto & Largura média dos cladódios de $1^{\mathrm{a}}$ ordem & 0,0289 & \\
\hline Indireto & CM dos cladódios de $4^{\mathrm{a}}$ ordem & 0,2719 & $0,3014 *$ \\
\hline Indireto & Total das demais variáveis & 0,0005 & \\
\hline Direto & CM dos cladódios de $2^{\mathrm{a}}$ ordem & 0,041 & \\
\hline Indireto & CM dos cladódios de $4^{\mathrm{a}}$ ordem & 0,3225 & $0,3510^{*}$ \\
\hline Indireto & Total das demais variáveis & $-0,0127$ & \\
\hline Direto & Largura média dos cladódios de $2^{\mathrm{a}}$ ordem & 0,0292 & \\
\hline Indireto & CM dos cladódios de $4^{\mathrm{a}}$ ordem & 0,2895 & $0,3789 *$ \\
\hline Indireto & Total das demais variáveis & 0,0601 & \\
\hline Direto & EM dos cladódios de $2^{\mathrm{a}}$ ordem & 0,0647 & \\
\hline Indireto & CM dos cladódios de $4^{\mathrm{a}}$ ordem & 0,3094 & $0,4162 *$ \\
\hline Indireto & Total das demais variáveis & 0,0213 & \\
\hline Direto & PM dos cladódios de $2^{\text {a }}$ ordem & $-0,009$ & \\
\hline Indireto & CM dos cladódios de $4^{\mathrm{a}}$ ordem & 0,3564 & $0,4162 *$ \\
\hline Indireto & Total das demais variáveis & 0,0689 & \\
\hline Direto & CM dos cladódios de $3^{\mathrm{a}}$ ordem & $-0,4699$ & \\
\hline Indireto & PM dos cladódios de $3^{\text {a }}$ ordem & 0,4616 & $0,2953 *$ \\
\hline Indireto & Total das demais variáveis & 0,3036 & \\
\hline Direto & EM dos cladódios de $3^{\text {a }}$ ordem & $-0,0184$ & \\
\hline Indireto & CM dos cladódios de $4^{\mathrm{a}}$ ordem & 0,3024 & $0,3286^{*}$ \\
\hline Indireto & Total das demais variáveis & 0,0446 & \\
\hline Direto & PM dos cladódios de $3^{\mathrm{a}}$ ordem & 0,4762 & \\
\hline Indireto & PM dos cladódios de $4^{\mathrm{a}}$ ordem & $-0,4344$ & $0,3076^{*}$ \\
\hline Indireto & Total das demais variáveis & 0,2658 & \\
\hline Direto & CM dos cladódios de $4^{\mathrm{a}}$ ordem & 0,6987 & \\
\hline Indireto & PM dos cladódios de $4^{\mathrm{a}}$ ordem & $-0,6792$ & $0,3260 *$ \\
\hline Indireto & Total das demais variáveis & 0,3064 & \\
\hline Direto & PM dos cladódios de $4^{\mathrm{a}}$ ordem & $-0,7021$ & \\
\hline Indireto & CM dos cladódios de $4^{\mathrm{a}}$ ordem & 0,6759 & $0,2679 *$ \\
\hline Indireto & Total das demais variáveis & 0,2941 & \\
\hline \multicolumn{2}{|c|}{ Coeficiente de determinação $\left(\mathrm{R}^{2}\right)$} & & 0,2921 \\
\hline \multicolumn{2}{|c|}{ Efeito da variável residual } & & 0,8414 \\
\hline
\end{tabular}

*Significativo pelo teste $\mathrm{t}$, a $5 \%$ de probabilidade. CM, comprimento médio. EM, espessura média. PM, perímetro médio. 
Ao se assumir o rendimento como variável resposta, houve correlação significativa $(p<0,05)$ com 19 características morfológicas; contudo, apenas as variáveis altura $\mathrm{x}$ largura $(0,8698)$ e número total de cladódios $(0,9438)$ apresentaram correlação alta (Tabela 3). Percebeu-se que as características morfológicas explicaram $95,20 \%$ da variabilidade do rendimento do clone Miúda, com maior influência do número total de cladódios, tanto com efeitos diretos quanto indiretos.

As características morfológicas explicativas do clone Miúda, embora significativas, resultaram em baixa correlação com o índice de área do cladódio, o que mostra que outras características podem estar influenciando essa variável. Ao se realizar o desdobramento dos seus efeitos, observou-se que o comprimento dos cladódios de quarta ordem (efeito direto e positivo sobre o índice de área do cladódio) e o perímetro médio dos cladódios de terceira e quarta ordem (efeito direto e indireto) são os principais contribuintes no índice de área do cladódio. $\mathrm{O}$ clone Miúda destaca-se por sua elevada quantidade de cladódios terciários e quaternários, com quatro anos e oito meses de idade. Isso explica a maior contribuição dessas variáveis no índice de área do cladódio. Silva et al. (2010) mostraram contribuições das características comprimento e largura dos cladódios de primeira e segunda ordem, principalmente em resposta ao efeito indireto da altura da planta, as quais são responsáveis pela sustentação da cultura.

Apesar da baixa influência das características morfogênicas sobre o índice de área do cladódio do clone Miúda, as variáveis explicativas apresentaram importância expressiva no rendimento (95\%), com destaque para o número total de cladódios e o perímetro médio dos cladódios de quarta ordem. O número superior de cladódios do clone Miúda em relação às demais variedades já foi observado por Leite (2009), o que justifica a elevação da produção de massa fresca e seca desse clone. A alta contribuição dos cladódios de quarta ordem no rendimento está associada ao sombreamento dos cladódios inferiores e à menor idade dos cladódios de ordens superiores (Dubeux Junior et al., 2006).

As variáveis morfológicas altura $\mathrm{x}$ largura; número total de cladódios; comprimento, largura, espessura e perímetro dos cladódios de primeira ordem; espessura dos cladódios de segunda e terceira ordem; e largura dos cladódios de quarta ordem do clone Orelha de Elefante Mexicana apresentaram correlação positiva em relação ao índice de área do cladódio (Tabela 4). Embora apresentassem correlação positiva, essas variáveis foram classificadas como de baixa a média magnitude. As características morfológicas do clone Orelha de Elefante Mexicana explicaram 63,69\% do comportamento do índice de área do cladódio, com correlação moderada e positiva. A variável número total de cladódios apresentou maior efeito direto ou indireto.

A correlação com o rendimento mostrou 11 variáveis significativas, sendo que a característica número total de cladódios foi a que obteve maior correlação $(0,9569)$, seguida da altura x largura $(0,8228)$ (Tabela 5). O comprimento dos cladódios de quinta ordem foi a única variável morfológica que apresentou correlação negativa $(-0,4911)$. A correlação relacionada ao rendimento mostrou que as variáveis analisadas responderam por $94,27 \%$ de sua variabilidade. Assim como nos outros clones, o número total de cladódios foi a variável de maior importância, com efeitos diretos e indiretos. Neder et al. (2013) encontraram relações de $82 \%$ entre a produtividade de acessos de O. ficus-indica e características morfológicas.

Para o clone Orelha de Elefante Mexicana, as características morfológicas também apresentaram correlação com o índice de área do cladódio, com destaque para o efeito direto do número total de cladódios. Porém, outras variáveis apresentaram boa participação no índice de área do cladódio, como comprimento e espessura dos cladódios de primeira ordem, espessura dos cladódios de segunda e terceira ordem, e largura dos cladódios de quarta ordem, as quais podem ser usadas como características de avaliação da capacidade fotossintetizante da cultura. $\mathrm{O}$ número total de cladódios apresenta correlação positiva com o índice de área do cladódio, enquanto o comprimento médio dos cladódios de primeira ordem pode ser explicado pelo hábito de crescimento semiaberto do clone, o que favorece a emergência de cladódios primários, resultantes da conformação e do tamanho dos cladódios basais (Leite, 2009).

As variáveis morfológicas apresentaram alta influência sobre o rendimento da cultura, com ênfase para o índice de área do cladódio, que variou em função do clone, mas também depende das condições 
Tabela 3. Desdobramento das correlações fenotípicas do rendimento do clone Miúda de palma forrageira (Nopalea cochenillifera), com quatro anos e oito meses de idade, em condições de sequeiro no semiárido brasileiro.

\begin{tabular}{|c|c|c|c|}
\hline Efeito & Variável explicativa & r parcial & $\mathrm{r}$ total \\
\hline Direto & Índice de área do cladódio & 0,0068 & \\
\hline Indireto & Número total de cladódios & 0,3185 & $0,4721^{*}$ \\
\hline Indireto & Total das demais variáveis & 0,1466 & \\
\hline Direto & Altura $\mathrm{x}$ largura & 0,0962 & \\
\hline Indireto & Número total de cladódios & 0,5674 & $0,8698^{*}$ \\
\hline Indireto & Total das demais variáveis & 0,2060 & \\
\hline Direto & Número total de cladódios & 0,6750 & \\
\hline Indireto & PM dos cladódios de $4^{\mathrm{a}}$ ordem & 0,2064 & $0,9438^{*}$ \\
\hline Indireto & Total das demais variáveis & 0,0623 & \\
\hline Direto & EM dos cladódios de $1^{\mathrm{a}}$ ordem & $-0,0730$ & \\
\hline Indireto & Número total de cladódios & 0,3163 & $0,5118^{*}$ \\
\hline Indireto & Total das demais variáveis & 0,2686 & \\
\hline Direto & PM dos cladódios de $1^{\mathrm{a}}$ ordem & 0,0701 & \\
\hline Indireto & Número total de cladódios & 0,1470 & $0,2850 *$ \\
\hline Indireto & Total das demais variáveis & 0,0677 & \\
\hline Direto & CM dos cladódios de $2^{\mathrm{a}}$ ordem & 0,0762 & \\
\hline Indireto & Número total de cladódios & 0,3500 & $0,5952 *$ \\
\hline Indireto & Total das demais variáveis & 0,1690 & \\
\hline Direto & Largura média dos cladódios de $2^{\mathrm{a}}$ ordem & $-0,0579$ & \\
\hline Indireto & Número total de cladódios & 0,3716 & $0,5621 *$ \\
\hline Indireto & Total das demais variáveis & 0,2486 & \\
\hline Direto & EM dos cladódios de $2^{\mathrm{a}}$ ordem & 0,1264 & \\
\hline Indireto & Número total de cladódios & 0,4362 & $0,6924 *$ \\
\hline Indireto & Total das demais variáveis & 0,1298 & \\
\hline Direto & PM dos cladódios de $2^{\mathrm{a}}$ ordem & $-0,0182$ & \\
\hline Indireto & Número total de cladódios & 0,4503 & $0,7100^{*}$ \\
\hline Indireto & Total das demais variáveis & 0,2778 & \\
\hline Direto & CM dos cladódios de $3^{\mathrm{a}}$ ordem & 0,1861 & \\
\hline Indireto & Número total de cladódios & 0,3589 & $0,6437^{*}$ \\
\hline Indireto & Total das demais variáveis & 0,0987 & \\
\hline Direto & Largura média dos cladódios de $3^{\mathrm{a}}$ ordem & 0,0251 & \\
\hline Indireto & Número total de cladódios & 0,2880 & $0,5504 *$ \\
\hline Indireto & Total das demais variáveis & 0,2373 & \\
\hline Direto & EM dos cladódios de $3^{\mathrm{a}}$ ordem & 0,0010 & \\
\hline Indireto & Número total de cladódios & 0,3529 & $0,5669^{*}$ \\
\hline$\underline{\text { Indireto }}$ & Total das demais variáveis & 0,2131 & \\
\hline Direto & PM dos cladódios de $3^{\mathrm{a}}$ ordem & $-0,0497$ & \\
\hline Indireto & Número total de cladódios & 0,3481 & $0,6354^{*}$ \\
\hline Indireto & Total das demais variáveis & 0,3369 & \\
\hline Direto & CM dos cladódios de $4^{\mathrm{a}}$ ordem & $-0,2104$ & \\
\hline Indireto & Número total de cladódios & 0,3375 & $0,6057^{*}$ \\
\hline Indireto & Total das demais variáveis & 0,4784 & \\
\hline Direto & Largura média dos cladódios de $4^{\mathrm{a}}$ ordem & $-0,2251$ & \\
\hline Indireto & Número total de cladódios & 0,2339 & $0,4235^{*}$ \\
\hline Indireto & Total das demais variáveis & 0,4149 & \\
\hline Direto & EM dos cladódios de $4^{\mathrm{a}}$ ordem & 0,0030 & \\
\hline Indireto & Número total de cladódios & 0,2115 & $0,3974 *$ \\
\hline Indireto & Total das demais variáveis & 0,1831 & \\
\hline Direto & PM dos cladódios de $4^{\mathrm{a}}$ ordem & 0,4545 & \\
\hline Indireto & Número total de cladódios & 0,3066 & $0,5670^{*}$ \\
\hline Indireto & Total das demais variáveis & $-0,1940$ & \\
\hline Direto & CM dos cladódios de $5^{\mathrm{a}}$ ordem & 0,1928 & \\
\hline Indireto & Número total de cladódios & 0,2755 & $0,4627^{*}$ \\
\hline Indireto & Total das demais variáveis & $-0,0057$ & \\
\hline Direto & PM dos cladódios de $5^{\text {a }}$ ordem & $-0,1894$ & \\
\hline Indireto & Número total de cladódios & 0,2173 & $0,3702 *$ \\
\hline Indireto & Total das demais variáveis & 0,3425 & \\
\hline \multicolumn{3}{|c|}{ Coeficiente de determinação $\left(\mathrm{R}^{2}\right)$} & 0,9520 \\
\hline \multicolumn{3}{|c|}{ Efeito da variável residual } & 0,2191 \\
\hline
\end{tabular}

edafoclimáticas e da densidade populacional (Ramos et al., 2011). O número total de cladódios também apresentou alto efeito indireto sobre o rendimento; já o comprimento médio dos cladódios de primeira ordem apresentou efeito negativo e indireto. Silva et al. (2010), ao avaliarem o efeito de características de clones de palma forrageira no rendimento, constataram que as de maior importância foram altura e largura das plantas, diferente do observado no presente trabalho para o clone Orelha de Elefante Mexicana. Portanto, essas características morfológicas não devem ser utilizadas na escolha de clones mais

Tabela 4. Desdobramento das correlações fenotípicas do índice de área do cladódio do clone Orelha de Elefante Mexicana de palma forrageira (Opuntia stricta), com quatro anos de idade, em condições de sequeiro no semiárido brasileiro.

\begin{tabular}{|c|c|c|c|}
\hline Efeito & Variável explicativa & r parcial & $\mathrm{r}$ total \\
\hline Direto & Altura x largura & 0,0143 & \\
\hline Indireto & Número total de cladódios & 0,3770 & $0,5817 *$ \\
\hline Indireto & Total das demais variáveis & 0,1904 & \\
\hline Direto & Número total de cladódios & 0,4676 & \\
\hline Indireto & EM dos cladódios de $2^{\mathrm{a}}$ ordem & $-0,1317$ & $0,6910^{*}$ \\
\hline Indireto & Total das demais variáveis & 0,3552 & \\
\hline Direto & $\mathrm{CM}$ dos cladódios de $1^{\mathrm{a}}$ ordem & 0,2901 & \\
\hline Indireto & Número total de cladódios & 0,1656 & $0,4603 *$ \\
\hline Indireto & Total das demais variáveis & 0,0046 & \\
\hline Direto & Largura média dos cladódios de $1^{\mathrm{a}}$ ordem & $-0,0830$ & \\
\hline Indireto & $\mathrm{CM}$ dos cladódios de $1^{\mathrm{a}}$ ordem & 0,2118 & $0,3114 *$ \\
\hline Indireto & Total das demais variáveis & 0,1826 & \\
\hline Direto & EM dos cladódios de $1^{\mathrm{a}}$ ordem & 0,3084 & \\
\hline Indireto & Número total de cladódios & 0,1953 & $0,4759 *$ \\
\hline Indireto & Total das demais variáveis & $-0,0279$ & \\
\hline Direto & PM dos cladódios de $1^{\mathrm{a}}$ ordem & 0,0686 & \\
\hline Indireto & $\mathrm{CM}$ dos cladódios de $1^{\mathrm{a}}$ ordem & 0,2492 & $0,4028 *$ \\
\hline Indireto & Total das demais variáveis & 0,0850 & \\
\hline Direto & EM dos cladódios de $2^{\mathrm{a}}$ ordem & $-0,2826$ & \\
\hline Indireto & Número total de cladódios & 0,2179 & $0,3374 *$ \\
\hline Indireto & Total das demais variáveis & 0,4021 & \\
\hline Direto & EM dos cladódios de $3^{\mathrm{a}}$ ordem & 0,2131 & \\
\hline Indireto & Número total de cladódios & 0,1736 & $0,3686^{*}$ \\
\hline Indireto & Total das demais variáveis & $-0,0181$ & \\
\hline Direto & Largura média dos cladódios de $4^{\mathrm{a}}$ ordem & 0,1293 & \\
\hline Indireto & Número total de cladódios & 0,1234 & $0,3102 *$ \\
\hline Indireto & Total das demais variáveis & 0,0575 & \\
\hline \multicolumn{3}{|c|}{ Coeficiente de determinação $\left(\mathrm{R}^{2}\right)$} & 0,6369 \\
\hline \multicolumn{3}{|c|}{ Efeito da variável residual } & 0,6026 \\
\hline
\end{tabular}

*Significativo pelo teste $\mathrm{t}$, a $5 \%$ de probabilidade. EM, espessura média. $\mathrm{CM}$, comprimento médio. PM, perímetro médio. 
produtivos. Neder et al. (2013) demonstraram que, apesar da não existência de correlações significativas entre a produtividade e o conteúdo de matéria seca de acessos de $O$. ficus-indica, é possível a seleção indireta de variedades mais produtivas por meio de caracteres morfológicos.

Tabela 5. Desdobramento das correlações fenotípicas do rendimento do clone Orelha de Elefante Mexicana de palma forrageira (Opuntia stricta), com quatro anos de idade, em condições de sequeiro no semiárido brasileiro.

\begin{tabular}{|c|c|c|c|}
\hline Efeito & Variável explicativa & $\mathrm{r}$ parcial & $\mathrm{r}$ total \\
\hline Direto & Índice de área do cladódio & $-0,0653$ & \\
\hline Indireto & Número total de cladódios & 0,5686 & $0,6711^{*}$ \\
\hline Indireto & Total das demais variáveis & 0,1678 & \\
\hline Direto & Índice de área do cladódio & 0,1070 & \\
\hline Indireto & Número total de cladódios & 0,6634 & $0,8228^{*}$ \\
\hline Indireto & Total das demais variáveis & 0,0524 & \\
\hline Direto & Índice de área do cladódio & 0,8228 & \\
\hline Indireto & Número total de cladódios & 0,0862 & $0,9569 *$ \\
\hline Indireto & Total das demais variáveis & 0,0479 & \\
\hline Direto & Índice de área do cladódio & 0,0685 & \\
\hline Indireto & $\mathrm{CM}$ dos cladódios de $1^{\mathrm{a}}$ ordem & 0,2913 & $0,4360^{*}$ \\
\hline Indireto & Total das demais variáveis & 0,0761 & \\
\hline Direto & Índice de área do cladódio & $-0,0826$ & \\
\hline Indireto & $\mathrm{CM}$ dos cladódios de $1^{\mathrm{a}}$ ordem & 0,2504 & $0,3674 *$ \\
\hline Indireto & Total das demais variáveis & 0,1996 & \\
\hline Direto & Índice de área do cladódio & 0,0849 & \\
\hline Indireto & $\mathrm{CM}$ dos cladódios de $1^{\mathrm{a}}$ ordem & 0,3437 & $0,4721^{*}$ \\
\hline Indireto & Total das demais variáveis & 0,0434 & \\
\hline Direto & Índice de área do cladódio & 0,1413 & \\
\hline Indireto & $\mathrm{CM}$ dos cladódios de $1^{\mathrm{a}}$ ordem & 0,2884 & $0,4349 *$ \\
\hline$\underline{\text { Indireto }}$ & Total das demais variáveis & 0,0053 & \\
\hline Direto & Índice de área do cladódio & $-0,0311$ & \\
\hline Indireto & $\mathrm{CM}$ dos cladódios de $1^{\mathrm{a}}$ ordem & 0,3835 & $0,5079 *$ \\
\hline Indireto & Total das demais variáveis & 0,1555 & \\
\hline Direto & Índice de área do cladódio & 0,0513 & \\
\hline Indireto & $\mathrm{CM}$ dos cladódios de $1^{\mathrm{a}}$ ordem & 0,3055 & $0,3879 *$ \\
\hline Indireto & Total das demais variáveis & 0,0310 & \\
\hline Direto & Índice de área do cladódio & 0,0272 & \\
\hline Indireto & $\mathrm{CM}$ dos cladódios de $1^{\mathrm{a}}$ ordem & $-0,4453$ & $-0,4911 *$ \\
\hline Indireto & Total das demais variáveis & $-0,0730$ & \\
\hline Direto & Índice de área do cladódio & 0,0371 & \\
\hline Indireto & $\mathrm{CM}$ dos cladódios de $1^{\mathrm{a}}$ ordem & 0,4229 & $0,5229 *$ \\
\hline$\underline{\text { Indireto }}$ & Total das demais variáveis & 0,0629 & \\
\hline \multicolumn{2}{|c|}{ Coeficiente de determinação $\left(\mathrm{R}^{2}\right)$} & & 0,9427 \\
\hline \multicolumn{2}{|c|}{ Efeito da variável residual } & & 0,2393 \\
\hline
\end{tabular}

*Significativo pelo teste $\mathrm{t}$, a $5 \%$ de probabilidade. CM, comprimento médio.

\section{Conclusões}

1. O índice de área do cladódio dos clones IPA Sertânia e Orelha de Elefante Mexicana de palma forrageira (Nopalea cochenillifera e Opuntia stricta, respectivamente) apresenta correlação alta e positiva com o número total de cladódios.

2. O perímetro médio dos cladódios de terceira ordem e o comprimento e o perímetro dos cladódios de quarta ordem são as variáveis mais importantes na expressão do índice de área do cladódio do clone Miúda de palma forrageira ( $N$. cochenillifera).

3. A variabilidade do rendimento da palma forrageira é mais influenciada pelo número total de cladódios, independentemente do clone avaliado.

\section{Agradecimentos}

Ao Conselho Nacional de Desenvolvimento Científico e Tecnológico (CNPq), pelo apoio financeiro (Processo no 476372/2012-7).

\section{Referências}

COSTA, N. de L.; GIANLUPPI, V.; MORAES, A. de. Produtividade de forragem e morfogênese de Trachypogon vestitus, durante o período seco, em área de cerrado, Roraima. Revista Trópica Ciências Agrárias e Biológicas, v.6, p.93-103, 2012.

CRUZ, C.D. GENES - a software package for analysis in experimental statistics and quantitative genetics. Acta Scientiarum. Agronomy, v.35, p.271-276, 2013. DOI: 10.4025/ actasciagron.v35i3.21251.

CRUZ, C.D.; REGAZZI, A.J.; CARNEIRO, P.C.S. Modelos biométricos aplicados ao melhoramento genético. 3.ed. Viçosa: Ed. da UFV, 2004. p.180-192.

DECKMYN, G.; NIJS, I.; CEULEMANS, R. A simple method to determine leaf angles of grass species. Journal of Experimental Botany, v.51, p.1467-1470, 2000. DOI: 10.1093/jexbot/51.349.1467.

DUBEUX JUNIOR, J.C.B.; SANTOS, M.V.F. dos; LIRA, M. de A.; SANTOS, D.C. dos; FARIAS, I.; LIMA, L.E.; FERREIRA, R.L.C. Productivity of Opuntia ficus-indica (L.) Miller under different $\mathrm{N}$ and $\mathrm{P}$ fertilization and plant population in north-east Brazil. Journal of Arid Environments, v.67, p.357-372, 2006. DOI: 10.1016/j.jaridenv.2006.02.015.

FAGUNDES, J.L.; SILVA, S.C. da; PEDREIRA, C.G.S.; CARNEVALLI, R.A.; CARVALHO, C.A.B. de; SBRISSIA, A.F.; PINTO, L.F. de M. Índice de área foliar, coeficiente de extinção luminosa e acúmulo de forragem em pastagens de Cynodon spp. sob lotação contínua. Pesquisa Agropecuária Brasileira, v.36, p.187-195, 2001. DOI: 10.1590/S0100-204X2001000100023.

FIRINCIOĞLU, H.K.; ÜNAL, S.; ERBEKTAŞ, E.; DOĞRUYOL, L. Relationships between seed yield and yield 
components in common vetch (Vicia sativa ssp. sativa) populations sown in spring and autumn in central Turkey. Field Crops Research, v.116, p.30-37, 2010. DOI: 10.1016/j.fcr.2009.11.005.

KUREK, A.J.; CARVALHO, F.I.F. de; ASSMANN, I.C.; MARCHIORO, V.S.; CRUZ, P.J. Análise de trilha como critério de seleção indireta para rendimento de grãos em feijão. Revista Brasileira de Agrociência, v.7, p.29-32, 2001.

LEITE, M.L. de M.V. Avaliação de clones de palma forrageira submetidos a adubações e sistematização de informações em propriedades do semiárido paraibano. 2009. 186p. Tese (Doutorado) - Universidade Federal da Paraíba, Areia.

LOPES, E.B.; BRITO, C.H. de; GUEDES, C.C.; SANTOS, D.C. dos; ARAÚJO, E.; BATISTA, J. de L.; ARAÚJO, L. de F.; VASCONCELOS, M.F. de; COELHO, R.S.B.; CAVALCANTI, V.A.L.B. Palma forrageira: cultivo, uso atual e perspectivas de utilização no Semiárido Nordestino. João Pessoa: Emepa/Faepa, 2007. 130p.

LU, G.-Y.; ZHANG, F.; ZHENG, P.-U.; CHENG, Y.; LIU, F.-I.; FU, G.-P.; ZHANG, X.K. Relationship among yield components and selection criteria for yield improvement in early rapeseed (Brassica napus L.). Agricultural Sciences in China, v.10, p.997-1003, 2011. DOI: 10.1016/S1671-2927(11)60086-2.

MALDANER, I.C.; HELDWEIN, A.B.; LOOSE, L.H.; LUCAS, D.D.P.; GUSE, F.I.; BORTOLUZZI, M.P. Modelos de determinação não-destrutiva da área foliar em girassol. Ciência Rural, v.39, p.1356-1361, 2009. DOI: 10.1590/ S0103-84782009000500008.

MARTINS, G. de A.; DOMINGUES, O. Estatística geral e aplicada. 4.ed. São Paulo: Atlas, 2011. 662p.

NEDER, D.G.; COSTA, F.R. da; EDVAN, R.L.; SOUTO FILHO, L.T. Correlations and path analysis of morphological and yield traits of cactus pear accessions. Crop Breeding and Applied Biotechnology, v.13, p.203-207, 2013. DOI: 10.1590/ S1984-70332013000300009.

OLIVEIRA JUNIOR, S. de; BARREIRO NETO, M.; RAMOS, J.P. de F.; LEITE, M.L. de M.V.; BRITO, E.A. de; NASCIMENTO, J.P. do. Crescimento vegetativo da palam forrageira (Opuntia fícus-indica) em função do espaçamento no Semiárido paraibano. Tecnologia e Ciência Agropecuária, v.3, p.7-12, 2009.

OLIVEIRA, F.T. de; SOUTO, J.S.; SILVA, R.P. da; ANDRADE FILHO, F.C. de; PEREIRA JUNIOR, E.B. Palma forrageira: adaptação e importância para os ecossistemas áridos e semiáridos. Revista Verde de Agroecologia e Desenvolvimento Sustentável, v.5, p.27-37, 2010.

OLIVEIRA, R.A. de; DAROS, E.; ZAMBON, J.L.C.; WEBER, H.; IDO, O.T.; BESPALHOK-FILHO, J.C.; ZUFFELLATO-RIBAS, K.C.; SILVA, D.K.T. da. Área foliar em três cultivares de cana-de-açúcar e sua correlação com a produção de biomassa. Pesquisa Agropecuária Tropical, v.37, p.71-76, 2007.

RAMOS, J.P. de F.; LEITE, M.L. de M.V.; OLIVEIRA JUNIOR, S. de; NASCIMENTO, J.P. do; ANTOS, E.M. Crescimento vegetativo de Opuntia ficus-indica em diferentes espaçamentos de plantio. Revista Caatinga, v.24, p.41-48, 2011.

RAO, P.S.; SARASWATHYAMMA, C.K.; SETHURAJ, M.R. Studies on the relationship between yield and meteorological parameters of para rubber tree (Hevea brasiliensis). Agricultural and Forest Meteorology, v.90, p.235-245, 1998. DOI:10.1016/ S0168-1923(98)00051-3.

SILVA, N.G. de M. e; LIRA, M. de A.; SANTOS, M.V.F. dos; DUBEUX JÚNIOR, J.C.B.; MELLO, A.C.L. de; SILVA, M. da C. Relação entre características morfológicas e produtivas de clones de palma-forrageira. Revista Brasileira de Zootecnia, v.39, p.2389-2397, 2010. DOI: 10.1590/S1516-35982010001100011.

TOEBE, M.; CARGNELUTTI FILHO, A. Multicollinearity in path analysis of maize (Zea mays L.). Journal of Cereal Science, v.57, p.453-462, 2013. DOI: 10.1016/j.jcs.2013.01.014.

VASCONCELOS, A.G.V. de; LIRA, M. de A.; CAVALCANTI, V.L.B.; SANTOS, M.V.F. dos; WILLADINO, L. Seleção de clones de palma forrageira resistentes à cochonilha do carmim (Dactylopius sp.). Revista Brasileira de Zootecnia, v.38, p.827-831, 2009. DOI: 10.1590/S1516-35982009000500007.

VENCOVSKY, R.; BARRIGA, P. Genética biométrica no fitomelhoramento. Ribeirão Preto: Sociedade Brasileira de Genética, 1992. 486p.

Recebido em 28 de abril de 2014 e aprovado em 3 de novembro de 2014 